\title{
ESTADO E POLÍTICAS DE FINANCIAMENTO EM EDUCAÇÃO
}

\author{
Carlos Roberto Jamil Cury*
}

\begin{abstract}
RESUMO: Pretende-se demonstrar que a atual forma vinculante de financiamento da educação básica, como o Fundo de Manutenção e Desenvolvimento da Educação Básica e Valorização dos Profissionais da Educação (FUNDEB), resulta de um entrelaçamento de três vertentes ou elos que vieram se constituindo ao longo da história da educação brasileira. Tais elos, por sua vez, implicam uma concepção social de Estado tensionada à sua vertente liberal. Esses elos condicionam o impacto das políticas de vertente liberal sobre a educação escolar.
\end{abstract}

Palavras-chave: Financiamento da educação. Estado e financiamento educacional. Políticas públicas e financiamento da educação.

\section{STATE AND FUNDING POLICIES IN EDUCATION}

ABSTRACT: This paper seeks to demonstrate that the current binding way of funding basic education through the Fundo de Manutenção e Desenvolvimento da Educação Básica e Valorização dos Profissionais da Educação (Fund for the Maintenance and Development of Basic Education - FUNDEB) originates from the intertwining of three aspects or links that have emerged along the history of Brazilian education. These links, as for them, imply a social conception of the State more influenced by liberalism. Such links govern the impact of the liberal policies on school education.

Key words: Education funding. State and educational funding. Public policies and education funding.

Doutor em Educação e professor do Departamento de Educação da Pontifícia Universidade Católica de Minas Gerais (PUC-MG).E-mail: crjcury.bh@terra.com.br 
A educação escolar, em nosso país, desde a Independência, esteve de alguma maneira ligada a políticas públicas desde que se considere essas últimas, entre outras coisas, como alguma forma de intervenção estatal na oferta e proteção de determinados direitos da cidadania. O Estado passa a ter um papel regulador no estabelecimento de uma política social ainda dentro de uma concepção liberal clássica. Tal é o caso da educação primária, como assinalado por clássicos do próprio liberalismo.

Refletindo o pensamento de clássicos como Adam Schmidt, Alfred Marshall e Stuart Mill, Marshall (1967, p. 73) afirma que "a educação é um pré-requisito necessário da liberdade civil" e, como tal, uma pré-condição do exercício de outros direitos. O Estado, neste caso, ao interferir no contractus, próprio do mercado, não estava conflitando com os direitos civis, porque o status de cidadão supôe pessoas inteligentes e de bom senso. O mesmo autor assinala: "A educação das crianças está diretamente relacionada com a cidadania, e, quando o Estado garante que todas as crianças serão educadas, este tem em mente, sem sombra de dúvida, as exigências e a natureza da cidadania” (p. 73).

Daí a instrução se tornar pública como função do Estado e, mais explicitamente, como dever do Estado, a fim de que, após o impulso interventor inicial que ela propicia, o indivíduo pudesse se autogovernar como ente dotado de liberdade e capaz de participar de uma sociedade de pessoas autônomas.

Esse impulso interventor, para além da gratuidade, pode se revestir de outras açóes como obrigatoriedade, assistência, diretrizes, autorização de funcionamento, planejamento e financiamento.

Não é objeto desse estudo a análise de todos esses pontos. Ele pretende descrever um aspecto forte dessa intervenção estatal na oferta de um direito da cidadania no Brasil: como se deu a presença (progressiva) da União no financiamento da educação escolar, seja por desembolso direto, seja por meio de uma complementação financeira face à exigência do ensino obrigatório para o que hoje se denomina ensino fundamental.

Pretende-se demonstrar que a atual forma vinculante de financiamento da educação básica, como o Fundo de Manutenção e Desenvolvimento da Educação Básica e Valorização dos Profissionais da Educação (FUNDEB), resulta de um entrelaçamento de três vertentes ou elos 
que vieram se constituindo ao longo da história da educação brasileira. Todavia, tais elos implicam uma concepção social de Estado tensionada à sua vertente liberal.

O primeiro elo dessa longa cadeia é a existência desse liame entre Constituição, impostos e recursos vinculados.

Segue-se, daí, a presença de uma burocracia presente no aparelho de Estado que, por meio de estudos técnicos, estatísticas e cálculos, ofereceu subsídios à tomada de decisões com relação às políticas educacionais.

Finalmente, buscar-se-á verificar a intervenção direta do aparato de Estado no âmbito empresarial por meio do salário-educação. Após a assinalação desses elos e seu eventual entrelaçamento, poder-se-á conceituar com mais propriedade uma face da presença do Estado na educação.

Tais vertentes serão consideradas a fim de se entender como se chegou a uma ligação entre as formas de financiamento obrigatório da educação e o estabelecimento de fundos para tal. Nessa direção, pretende-se não só alçar o papel determinante do Estado nesse assunto, como também evidenciar a originalidade derivada do FUNDEB e de seu predecessor, o Fundo de Manutenção e Desenvolvimento do Ensino Fundamental e Valorização do Magistério (FUNDEF).

\section{I}

A presença, ao mesmo tempo progressiva e limitada, da União em matéria de educação se articula com a descentralização do ensino e com o regime federativo.

Ao ampliar (ou não) o âmbito de sua presença, a União sempre oscilou entre um horizonte de um sistema nacional de educação (só existente entre 1824 e 1834) (Saviani, 2004) e um chão real de um sistema educacional descentralizado em sistemas de ensino, ${ }^{1}$ aí se destacando o sistema federal (antes: imperial) e os sistemas estaduais (antes: provinciais). ${ }^{2}$

Ora, o marco básico de uma intervenção estatal-nacional decisiva nos sistemas de ensino é a Constituição Federal de 1934. Entretanto, já antes, havia alguma definição ou iniciativa relativa a esse papel do Estado. A Constituição Imperial de 1824 acolhe o ensino primário 
como direito do cidadão (art. 179, XXXII), sob a forma de prestação estatal gratuita. O Império também não abriu mão do caráter oficial dos certificados e diplomas (Chizzotti, in: Fávero, 1996).

A Constituição Liberal de 1891 impõe a laicidade como característica inerente a todas as escolas públicas da União, estados e municípios, mantém o Estado como detentor da validade dos diplomas e certificados, mas retira de seu texto a gratuidade. Essa última ficou por conta do regime autônomo dos estados (Cury, 2001).

Já o financiamento da educação, pela via da União, comparece de modo pontual e precário em ordenamentos jurídicos negociados com os estados. É o caso, por exemplo, da iniciativa do governo federal em apoiar o desenvolvimento de escolas na zona rural nos estados, sob a forma de adesão e de contrapartida.

Assim, a Reforma João Alves/Rocha Vaz, por meio do Decreto n. 16.782/A, de 13 de janeiro de 1925, estabelecia o concurso da União para a difusão do ensino primário. De acordo com o artigo 25 do Decreto, a União deveria subsidiar parcialmente o salário dos professores primários em exercício nas escolas rurais. ${ }^{3}$ Caberia aos estadosmembros pagar o restante do salário, oferecer residência aos docentes, construir ou arranjar prédio escolar e fornecer o material didático. ${ }^{4}$

A situação começa a se alterar a partir da Revolução de 1930, especialmente com o processo sócio-político conducente à Assembléia Nacional Constituinte de 1933-1934. ${ }^{5}$ Ela estabeleceu, para todos os entes federativos, a gratuidade e a obrigatoriedade do (então) ensino primário, um Plano Nacional de Educação sob Diretrizes e Bases e uma vinculação porcentual para a educação advinda da arrecadação dos impostos. Tais constrangimentos se dão dentro de um capítulo próprio em que a educação é reconhecida como direito de todos (art. 150), sendo a sua oferta sujeita ao reconhecimento e fiscalização oficiais. Importa salientar os aspectos do financiamento obrigatório. A Constituição Federal de 1934, em seu artigo 156, assevera: "A União e os Municípios aplicarão nunca menos de dez por cento, e os Estados e o Distrito Federal nunca menos de vinte por cento, da renda resultante dos impostos, na manutenção e no desenvolvimento dos sistemas educativos".

Com efeito, políticas públicas sem recursos se tornam declaratórias e potencialmente inócuas. Essa vinculação representa um vetor distintivo para a conformação do direito à educação no Brasil, uma 
raridade em constituições de outros países, e a formalização de demandas cuja inserção nacional se reproduz nos dispositivos similares correntes nos estados. Junto a isso, é preciso referir-se ao clima de época, pelo qual se atribuía ao planejamento e aos planos dele decorrentes a possibilidade de superar ou ao menos atenuar os conflitos sociais, em boa parte nascidos da contradição entre trabalho e capital. Como diz Gomes (2003, p. 113-114):

Durante os anos 30, propostas para a instituição de um Estado forte e autoritário, que estavam sendo formuladas e debatidas no país havia mais de uma década, ganharam efetivo espaço político, acompanhadas de uma ideologia nacionalista que defendia o crescente centralismo e intervencionismo estatal em assuntos econômicos e sociais.

Já antes dos anos de 1930, essa dimensão intervencionista do Estado foi destacada na Revisão Constitucional de 1925-1926. Esse clima far-se-á presente também face à educação escolar, seja em vários movimentos civis e estatais (Nagle, 1974), seja nos discursos de parlamentares na Revisão de 1925-1926. Veja-se, por exemplo, a fala de Leopoldino de Oliveira, deputado por Minas Gerais:

Se verifica que a intervenção federal se faz necessária, sem peias outras, que não a do respeito à simultânea competência estadual e municipal, sem o que o Brasil ficará, pelo tempo de algumas geraçôes ainda, submerso na treva deusa do analphabetismo. (apud Cury, 2003, p. 75)

A esse desiderato, a Carta de 1934, além do determinado pelo artigo 156, determinará no artigo 157 :

A União, os Estados e o Distrito Federal reservarão uma parte de seus patrimônios territoriais para a formação dos respectivos fundos de educação.

$\$ 1^{\circ}$ - As sobras das dotações orçamentárias, acrescidas de doações, percentagens sobre o produto de vendas de terras públicas, taxas especiais e outros recursos financeiros constituirão, na União, nos Estados e nos Municípios, esses fundos especiais, que serão aplicados exclusivamente em obras educativas determinadas em lei.

$\$ 2^{\circ}$ - Parte dos mesmos fundos se aplicará em auxílio a alunos necessitados, mediante fornecimento gratuito de material escolar, bolsas de estudo, assistência alimentar, dentária e médica, e para vilegiaturas. ${ }^{6}$ 
Tal clima responde aos anseios de renovação educacional e social defendidos pelos profissionais renovadores, em especial no Manifesto dos Pioneiros da Educação Nova, quando este afirma:

A autonomia econômica não se poderá realizar, a não ser pela instituição de um "fundo especial ou escolar", que, constituído de patrimônios, impostos e rendas próprias, seja administrado e aplicado exclusivamente no desenvolvimento da obra educacional, pelos próprios órgãos de ensino, incumbidos de sua direção. (1932, p. 50)

Essa importância da educação escolar, tornada gratuita e obrigatória no primário em todo o país, só se viabilizaria se houvesse recursos públicos para mantê-la e desenvolvê-la. ${ }^{7}$ Por isso, a Constitução impõe a vinculação percentual a partir dos impostos arrecadados. E para que tal impositividade não ficasse sujeita à dispersividade e ao arbítrio de cada qual, a Constituição prevê uma lei nacional, competência privativa da União, expressa em um Plano Nacional de Educação (cf. Horta, in: Cury et al., 1997).

Importa assinalar aqui que o Estado interventor respondia também à idéia de planejamento, seja pela via da Rússia leninista, seja pela definição constitucional da República de Weimar, ${ }^{8}$ ou ainda pela via do Capitalismo keynesiano. Sobre esse último, Przeworski (1989, p. 53) destaca e analisa as mobilizações das esquerdas européias do período:

A revolução keynesiana - e foi verdadeiramente uma revolução - forneceu aos sociais-democratas um objetivo e, com isso a justificativa para seu papel no governo, simultaneamente transformando o significado ideológico de políticas distributivas que favoreciam a classe trabalhadora (...). A sociedade não estava à mercê dos caprichos do mercado capitalista, a economia podia ser controlada e o bem-estar dos cidadãos continuamente intensificado pelo papel ativo do Estado (...).

Posteriormente, por meio da Lei n. 378, em 13 de janeiro de 1937, a União justifica sua denominada ação supletiva, de acordo com os artigos 117 e 118 da mesma Lei, o desembolso de recursos voltados para a construção e manutenção de escolas primárias e profissionais em zonas rurais.

A Constituição (outorgada) de 1937 retirou a vinculação constitucional de recursos para a educação, tal como ocorrerá 30 anos mais tarde, já sob outro tipo de regime autoritário. ${ }^{9}$ 
A Constituição Federal (promulgada) de 1946 retoma, em boa parte, princípios da Constituição de 1934, como a vinculação de impostos para o financiamento da educação como direito de todos, a distinção entre a rede pública e a privada, a gratuidade e a obrigatoriedade do ensino primário. Repóe em termos federativos a autonomia dos estados na organização dos sistemas de ensino. Assim, no artigo 169, se lê: "Anualmente, a União aplicará nunca menos de dez por cento, e os Estados, o Distrito Federal e os Municípios nunca menos de vinte por cento da renda resultante dos impostos na manutenção e desenvolvimento do ensino". Por sua vez, o artigo 171 da nova Lei Maior expressa: "Os estados e o Distrito Federal organizarão os seus sistemas de ensino. $\$ único: Para o desenvolvimento desses sistemas, a União cooperará com auxílio pecuniário, o qual, em relação ao ensino primário, provirá do respectivo Fundo Nacional”.

Sob essa Constituição deu-se, em 1961, a Lei n. 4.024/61 das Diretrizes e Bases da Educação Nacional. Nela, a vinculação permanece e se amplia por estabelecer a necessidade de metas quantitativas e qualitativas, postas em um Plano Nacional de Educação. Cada nível de ensino contaria com Fundo, cuja elaboração estaria a cargo do Conselho Federal de Educação.

Essa Constituição foi bastante emendada após o golpe de 1964, fosse para instaurar um novo sistema tributário, fosse para incrementar um centralismo econômico e político da União, revogando a vinculação para a educação. São impostos à nação os Atos Institucionais, pelos quais, na verdade, foram suspensas as garantias constitucionais vigentes.

É dentro desse quadro que ao Congresso existente se atribui a tarefa de elaborar uma outra Constituição, adaptada ao modelo político autoritário e ao modelo econômico concentrador de renda. Aí a noção da ordem se sobrepõe à da liberdade e da justiça.

O capítulo da educação, condicionado ao clima da época, contempla alteraçōes significativas: o ensino primário, gratuito e obrigatório nos estabelecimentos oficiais incorpora explicitamente a faixa etária de 7 a 14 anos. Quer dizer: houve extensão da obrigatoriedade associada à faixa etária. Contudo, em nome do planejamento de orçamentos plurianuais, da "teoria do capital humano", da racionalização dos recursos, em nome da ordem moral e cívica, coloca-se, no seu artigo 65, inciso III, que, ressalvados os impostos únicos e as disposiçóes desta 
Constituição e de leis complementares, nenhum tributo terá a sua arrecadação vinculada a determinado órgão, fundo ou despesa.

Com isso, caiu a vinculação de impostos para o financiamento da educação escolar. Fala-se apenas em prestação de assistência técnico-financeira da União para com os estados.

Sob essa Constituição, se dá a Lei n. 5.540/68, da Reforma Universitária, uns poucos dias antes do AI-5, de 13 de dezembro de 1968. E não se pode esquecer que a ditadura elaborou muitos planos nacionais e regionais de desenvolvimento, nos quais comparecia a figura dos planos setoriais.

A Constituição de 1967, já fragilizada, ficou ainda mais com a chamada Emenda Constitucional n. 1 da Junta Militar, de 1969. Essa Emenda refaz a Constituição de 1967 à luz e à letra dos Atos Institucionais. A desvinculação de verbas permanece conquanto ela reapareça apenas para os municípios e fora do capítulo da Educação. Os municípios, já gravados com o sistema tributário então vigente, poderiam sofrer intervenção no caso de não aplicarem o percentual de $20 \%$ dos impostos no ensino primário de suas redes.

A emenda Calmon (EC n. 24/83), após sucessivas tentativas, repõe a vinculação cuja regulamentação só se dá por meio da Lei $n$. 7.348/85. A Constituição da República de 1988 afirma a educação como o primeiro dos direitos sociais (art. $6^{\circ}$ ), como direito civil e político (capítulo da Educação) e ela, como dever de Estado, é afirmada por muitos modos. O próprio ensino fundamental é consagrado como direito público subjetivo, e o ensino médio, na versão original, é posto como progressivamente obrigatório.

A vinculação reaparece e os programas suplementares de alimentação e saúde terão que ter outras fontes de receita que não os da manutenção do ensino

Essa Constituição conheceu a Emenda Constitucional n. 14/96, que subvincula os recursos vinculados no FUNDEF. Dessa emenda decorreu a Lei n. 9.424/96, regulamentadora deste Fundo e que foi antecedida por alguns dias pela LDB n. 9394/96.

Pela Lei n. 10.172, de janeiro de 2001, seguindo o imperativo do artigo 214 da Constituição, o Congresso aprovou o Plano Nacional de Educação (PNE). O Plano oficial, ainda que menos ousado do que 
aquele proposto por entidades educacionais, tem um diagnóstico realista da educação nacional e estabelece metas aceitáveis para serem atingidas com vistas ao acesso, permanência e qualidade da educação. Contudo, a força da área econômica impediu a aprovação de um aumento de recursos para as metas por meio dos vetos da Presidência da República. Sem recursos, o PNE tornou-se um ato declaratório.

A Emenda Constitucional n. 53/06 criou o FUNDEB e, repetindo o FUNDEF, assinala a necessidade de um padrão de qualidade de ensino nacionalmente definido. Tramita no Congresso Nacional um projeto de conversão da Medida Provisória em Lei, a fim de regulamentar essa Emenda Constitucional.

A desvinculação de recursos financeiros em 1937 representou um grave atentado para as políticas públicas de manutenção e desenvolvimento da educação. Mas, não se pode ignorar, por outro lado, iniciativas de uma certa burocracia dentro Estado Novo. ${ }^{10}$

Apesar da repressão e censura no período, havia grande expectativa com relação aos avanços tecnológicos advindos do desenvolvimento científico. Havia uma crença na solução dos problemas vividos por meio do progresso científico, abrindo-se espaço para a "racionalidade" trazida pelos técnicos.

A Constituição Federal de 1934 havia constituido órgãos técnico-consultivos da Câmara e do Senado, denominados Conselhos Técnicos (cf. art. 91, V da Constituição). Todos os ministérios seriam também assistidos por um ou mais Conselhos Técnicos. No caso da Educação, o artigo 152 da Constituição de 1934 constitui o Conselho Nacional de Educação.

Com isso, fica mais claro o segundo elo importante do escopo desse estudo. Citando o posicionamento da Associação Brasileira de Educação (ABE), cujo teor será lícito estender para o clima da época, diz Horta (1997, p. 141):

Naquele momento era muito forte, entre os educadores da ABE, a crença de que as decisões no campo da educação se imporiam pela sua racionalidade técnica, e que esta mesma racionalidade garantiria a autonomia política dos educadores e dos órgãos de Educação. 
Urge destacar, como exemplo, a figura de Teixeira de Freitas, que, à frente da Secretaria de Estudos Estatísticos do Ministério da Educação e Saúde, estabeleceu a coleta racionalizada dos dados estatísticos da educação. À vista dos dados preocupantes revelados pelo Serviço de Estatística, Freitas ${ }^{11}$ subsidia a $1^{\text {a }}$ Conferência Nacional de Educação de $1941,{ }^{12}$ apontando a necessidade de se retornar à vinculação orçamentária para a educação. É o que se dá com o Decreto-Lei n. 4.958, de 12 de novembro de 1942, instituindo o Fundo Nacional do Ensino Primário advindo de tributos federais criados para esse fim. A ampliação e melhoria do sistema escolar primário de todo o país eram seus objetivos. Veja-se:

Art. $3^{\circ}$ - Os recursos do Fundo Nacional de Ensino Primário se destinarão à ampliação e melhoria do sistema escolar primário de todo o país. Esses recursos serão aplicados em auxílios a cada um dos Estados e Territórios e ao Distrito Federal, na conformidade de suas maiores necessidades.

Esse mesmo Decreto previa também que os auxílios federais estariam sujeitos a um Convênio Nacional do Ensino Primário, assinado em novembro de 1942, pelo ministro da Educação e representantes dos estados. Tal Convênio só seria acionado pelo Decreto-Lei n. 5.293, em $1^{\circ}$ de março de 1943.

Art. $1^{\circ}$ - Fica ratificado o Convênio Nacional de Ensino Primário, de que trata o art. $4^{\circ}$ do decreto-lei n. 4.958, de 14 de novembro de 1942, e celebrado, a 16 de novembro de 1942, entre o Ministro da Educação e os chefes ou delegados dos governos dos Estados, do Distrito Federal e do Território do Acre.

A União prestaria assistência técnica e financeira no desenvolvimento deste ensino nos estados, desde que estes aplicassem um mínimo de $15 \%$ da renda proveniente de seus impostos em ensino primário, chegando-se a $20 \%$ em 5 anos. Por sua vez, os estados se obrigavam a fazer convênios similares com os municípios, mediante decreto-lei estadual, visando repasse de recursos, desde que houvesse uma aplicação mínima inicial de $10 \%$ da renda advinda de impostos municipais em favor da educação escolar primária, chegando-se a 15\% em 5 anos.

Somente por meio do Decreto-Lei n. 6.785, de 11 de agosto de 1944, o governo federal criou a fonte federal de onde haveria de tirar 
os seus recursos para a efetivação do Convênio por meio de taxas do imposto de consumo incidente sobre bebidas.

Foi preciso um outro decreto que regulamentasse o Decreto-Lei n. 4.958 de 1942 e fizesse chegar aos estados a verba que a União propiciaria, a fim de apoiar a ampliação do ensino primário. O DecretoLei n. 8.529, de 2 de janeiro de 1946, Lei Orgânica do Ensino Primário, extinto o Estado Novo, mantém a presença da União nos termos do Decreto-Lei n. 4958/42.

Provavelmente em função desses artigos da Constituição, o governo constitucional de Eurico Gaspar Dutra, junto com o ministro Clemente Mariani exaram o Decreto n. 24.191, de 10 de dezembro de 1947, que dá nova redação aos artigos $4^{\circ}$ e $5^{\circ}$ do Decreto n. $19.513 / 45$.

Art. $4^{\circ}$ - Os auxílios federais, provenientes do Fundo Nacional do Ensino Primário, serão aplicados nos termos seguintes:

I - A importância correspondente a 70\% do auxílio federal destinar-se-á a construções e reconstruções de prédios escolares, e à aquisição de equipamento didático, observados os têrmos do plano que for elaborado pelo Instituto Nacional de Estudos Pedagógicos e aprovado pelo Ministro de Estado. As obras serão executadas pela unidade federativa interessada ou, quando conveniente, a critério do Ministro Estado, pela administração federal. Correrão a conta dessa parcela as despesas referentes à execução do plano e fiscalização das obras.

II - A importância correspondente a $25 \%$ do auxílio federal será aplicada na educação primária de adolescentes e adultos analfabetos, observados os termos do plano de ensino supletivo que for aprovado pelo Ministro de Estado.

III - A importância correspondente a 5\% do auxilio federal será aplicada na concessão de Bolsas de Estudo, na manutenção de cursos destinados à formação e aperfeiçoamento de pessoal docente e técnico-especializado de ensino primário e normal e no funcionamento de classes de ensino primário destinadas à demonstração de prática pedagógica, na forma do plano que for organizado pelo Instituto Nacional de Estudos Pedagógicos e aprovado pelo Ministro de Estado.

Art. $5^{\circ}$ - A concessão do auxilio federal dependerá, nos casos das alíneas I, do artigo anterior, de acôrdo celebrado entre o Ministério da Educação e Saúde e o representante devidamente autorizado da unidade federativa interessada, atendidos os critérios gerais indicados nos artigos anteriores, e mediante prévia autorização do Presidente da República. 
$\$ 1^{\circ}$ - Os acordos serão assinados anualmente, em qualquer época, tendo em vista as disponibilidades do Fundo Nacional de Ensino Primário.

$\$ 2^{\circ}$ - Ao Ministério da Educação e Saúde incumbirá fiscalizar, em todos os seus têrmos, a execução dos acordos celebrados na forma do presente artigo.

Em 1955, por meio do Decreto n. 37.082, de 24 de março, houve outra regulamentação da aplicação dos recursos destinados ao Fundo do Ensino Primário. Dos recursos existentes no Fundo, 70\% dos mesmos aplicar-se-iam em construções escolares e equipamento didático; $25 \%$ destinar-se-iam à alfabetização de jovens e adultos e 5\% para bolsas de estudos voltadas para a capacitação de pessoal docente e técnico-administrativo, com critérios estabelecidos pelo então Instituto Nacional de Estudos Pedagógicos (INEP).

A versão final da Lei n. 4.024/61, além de confirmar a vinculação constitucional orçamentária, incumbiu, em seu artigo 92, o agora Conselho Federal de Educação dos procedimentos voltados à feitura do Plano Nacional de Educação, por meio de metas e fundos para cada nível de ensino. Elaborado em 1962, o Plano Nacional seria referido a cada fundo e com execução prevista dentro de um prazo determinado. As verbas seriam vinculadas a planos específicos e com metas quantitativas e qualitativas. Segundo Celso Kelly (1963, p. 11), “o plano se encaixa na ciência da administração de que os serviços de interesse público devem resultar obrigatoriamente de planificações". Ainda segundo o mesmo educador:

(...) coube a Anísio Teixeira articular, num só documento, as metas quantitativas e qualitativas, as normas reguladoras da distribuição dos fundos nacionais do ensino primário e do ensino médio e as razões que impediam a formulação quanto ao ensino superior. (Idem, ibid.)

Também o artigo 95 da LDB/61 estabelecia: "A União dispensará a sua cooperação financeira ao ensino sob a forma de: subvenção, de acordo com as leis especiais em vigor (...)". Sob essas inspirações gerais e determinações legais, Anísio Teixeira, ${ }^{13}$ em $A$ educação é direito (1968), busca articular o caráter público da escola com sua democratização e com um financiamento estatal. Diz ele:

(...) os serviços de educação constituam serviços autônomos, de responsabilidade conjunta da União, dos Estados e dos Municípios, superintendidos por Conselhos representativos da sociedade e de composição leiga 
(...). Os recursos mínimos previstos na Constituição para tais serviços passariam a ser considerados Fundos de Educação a serem administrados pelos Conselhos. (p. 81)

Tomando como fundamento a importância do ensino primário para a configuração do direito à educação, Teixeira (1968, p. 56) assinala como competência comum dos entes federativos a prestação dessa obrigação:

(...) a escola primária teria uma dimensão federal pelo cumprimento das diretrizes e bases federais, estadual, pela organização e pelo magistério, cuja formação e licenciamento ficariam atribuídos, privativamente, aos Estados, e municipal, pela sua imediata direção e administração e por tudo isto, nacional-brasileira.

Para ele, a população escolarizável teria como base para o financiamento da educação pública o conceito de custo aluno/ano, para cujo concurso haveria a participação dos três níveis administrativos do poder público no financiamento da unidade escolar.

Para esse "custo-padrão" contribuiriam, com efeito, as três quotas: a municipal, correspondente ao resultado da divisão dos $20 \%$ de sua receita tributária pelas crianças escolarizáveis, em virtude da obrigatoriedade escolar; a estadual, correspondente ao resultado da divisão de $14 \%$ de sua receita tributária por esse mesmo número de crianças; e a da União, correspondente ao que faltasse para completar o total do custo-padrão do aluno/ano, no serviço comum do ensino primário. (Idem, ibid., p. 82)

A valorização do professor, por meio da elevação do seu salário e da atribuição da importância à formação e licenciamento do magistério, teria o condão de fortalecer a unidade escolar. Diz Teixeira (op. cit., p. 82): "A formação e o licenciamento do magistério seriam da competência exclusiva dos Estados, sem prejuízo do poder regulamentador das profissões conferido pela Constituição à União".

A unidade escolar pública articular-se-ia com a comunidade, por intermédio de uma gestão constituída de órgãos colegiados. Diz o autor (p. 66):

O fato de se fazer pública a educação não lhe retira o caráter de serviço em estreita articulação com a sociedade. A sociedade é mais ampla do que o Estado. Quando as circunstâncias a levam a transferir ou confiar ao Estado o 
ônus de ministrar e manter o ensino, a delegação é feita no pressuposto de serem dadas à escola as condições necessárias para o seu mais adequado flincionamento, no interesse geral da sociedade.

Essa proposta de gestão da educação pública consagra o caráter autônomo da escola, abriga seu financiamento federativo e convoca a comunidade a compartilhar dos destinos da escola. O planejamento da educação pública ficaria, pois, sob a forma de um Estado Democrático de Direito.

\section{III}

O terceiro elo conducente ao conjunto do financiamento se impõe desde a Constituição de 1934, no seu artigo 139. Com efeito, ela dispunha sobre a responsabilidade de certas empresas com a educação escolar de seus empregados e dos seus filhos. Trata-se de uma forma de interferência estatal nas empresas nesse assunto, no caso de aí haver analfabetos.

Sob a Carta de 1937, conforme o artigo 129, a Consolidação das Leis do Trabalho (CLT), o Decreto-Lei n. 5.452/43 prevê, no artigo 399, diploma de benemerência às empresas que mantiverem creches e instituiçôes de proteção aos menores em idade pré-escolar... Quase na mesma orientação, o artigo 427 previa aos menores empregados a concessão obrigatória de tempo que for necessário para a freqüência às aulas. Já o $\$$ único desse artigo dispunha: "Os estabelecimentos situados em lugar onde a escola estiver a maior distância que dois quilômetros, e que ocuparem, permanentemente, mais de trinta menores analfabetos, de 14 a 18 anos, serão obrigados a manter local apropriado em que lhes seja ministrada a instrução primária”.

A empresa com tais características e que não cumprisse esse dispositivo incorria em penalidades expressas em multas. Esse dever das empresas vai se estendendo com maior clareza nas Constituições de 1946, 1967 e 1969. E é, ainda, sob a Constituição de 1946 e sob a LDB da lei n. 4.024/61 que esse dispositivo se converterá, formalmente, em uma nova fonte de recursos para a educação. A Constituição de 1946, no seu artigo 168, incisos III e IV, estabelece:

III - as empresas industriais, comerciais e agrícolas, em que trabalhem mais de cem pessoas, são obrigadas a manter ensino primário gratuito para os seus servidores e os filhos destes; 
IV - as empresas industriais e comerciais são obrigadas a ministrar, em cooperação, aprendizagem aos seus trabalhadores menores, pela forma que a lei estabelecer, respeitados os direitos dos professores (...).

A lei n. 4.024/61 dispõe que os recursos federais destinados à educação (nove décimos) constituirão, em parcelas iguais, os Fundos Nacionais do ensino primário, do ensino médio e ensino superior. Determina, ainda, que o Conselho Federal de Educação elabore o Plano Nacional de Educação referente a cada Fundo. Assim, em 1962, o CFE entregou ao MEC o primeiro Plano Nacional de Educação, que estabelecia objetivos e metas para um período de 8 anos. Com o Plano, estabelecem-se metas qualitativas e quantitativas para a educação, o que permite tanto uma revisão dos valores quanto uma previsão mais precisa de recursos para o PNE.

Desse modo, o Poder Executivo tinha o desafio de cumprir a obrigação constitucional da escolaridade obrigatória, sob as leis vigentes, perseguindo as metas estabelecidas no PNE, tais como a matrícula até a quarta série de $100 \%$ da população escolar de 7 a 11 anos e matrícula, na quinta e sexta séries, de $70 \%$ da população de 12 a 14 anos. Além de fixar o atendimento de $100 \%$ da população escolarizável, o Plano estende a escolarização obrigatória até aos 14 anos. Essa meta, junto com a de erradicar o analfabetismo, exigiria mais disponibilidade financeira com aporte de novas fontes de recursos.

O salário-educação, terceiro elo da cadeia, fechava esse conjunto. Para a sua configuração, destaque-se o professor Carlos Pasquale, herdeiro de uma tradição ligada à educação pública. Estudioso do assunto, ele formula uma proposta de novo mecanismo de financiamento que poderia trazer mais recursos necessários à expansão do ensino.

Abraçando a proposta, o Executivo encaminha ao Congresso projeto de lei que se torna a Lei n. 4.440/64, regulamentada pelo Decreto n. 55.551, de 12 de janeiro de 1965, alterado pelo Decreto n. 58.093, de 28 de março de 1966. É a lei do salário-educação. Trata-se de uma contribuição compulsória devida pelas empresas, destinada a suplementar os recursos públicos reservados para o ensino primário.

A Lei introduz uma nova variável no apoio à educação: a determinação do custo do ensino primário por aluno. O Instituto Nacional de Estudos Pedagógicos (INEP) foi acionado para realizar estudos com esse fim. Vale a pena citar alguns desses cálculos feitos pelo professor Pasquale (1965, p. 21): 
Admitindo-se que: a) se atribua ao professor das classes de ensino primário a remuneração equivalente a 1,5 salário-mínimo (SM); b) as despesas com a remuneração do professor correspondam a $70 \%$ do custo total da manutenção desse ensino, sendo os 30\% restantes representados pelas despesas de livros e material escolar (13\%), prédio e equipamento (10\%), direção e supervisão do ensino ( 7\%); c) a matrícula média por classe seja de 30 alunos, o custo mensal per capita do ensino primário, em cada região do país, será dado pela fórmula:

$$
\frac{1,5 S M}{70} \times \frac{100}{30}=0,07 S M
$$

O custo do ensino primário assim determinado ( $7 \%$ do salário mínimo) será devido pelas empresas em relação a cada um dos filhos de empregados em idade de escolarização obrigatória.

De acordo com as estimativas atuariais realizadas pelo Ministério do Trabalho e Previdência Social, e com índices etários aplicados ao Censo de 1960, correspondem a cada 100 filiados aos diversos Institutos de Previdência Social 30 menores de 7 a 11 anos de idade. A contribuição relativa a cada empregado ativo deverá ser, então, 30\% do custo do ensino primário de uma criança, isto é:

$$
\frac{30}{100} \times \frac{(7 S M)}{100}=0,02 S M
$$

A contribuição assim fixada ( $2 \%$ do salário mínimo) é que constitui o chamado "salário-educação" e será arrecadada pelos Institutos de Previdência a que as empresas estiverem vinculadas.

O salário-educação, desde o seu estabelecimento, teve sua aplicação determinada em lei, com impacto federativo. A divisão entre Uniāo e estados buscava compensar as diferenças regionais. Desse modo, de onde houvesse maior arrecadação poder-se-ia retirar uma parte para uma redistribuição onde os recursos fossem menores. Isso ajudava a responder ao ditame da Lei de Diretrizes e Bases que determinava à União aplicar os $50 \%$ do seu recolhimento na razão direta dos indices de analfabetismo.

Outro dispositivo da Lei fixava a idade das crianças a serem atendidas e os valores atribuídos à contribuição (incisos I, II e III do artigo 8). A vinculação entre essas duas variáveis se dava de tal forma que qualquer alteração em uma delas implicaria proporcionalmente a alteração dos 
demais. Pretende-se com o dispositivo garantir o equilíbrio do sistema de custeio e abertura a revisóes periódicas a serem fixadas por decreto.

A Constituição Federal de 1988 dispõe, originalmente, sobre salário-educação no seu artigo $212, \mathbb{S} 5^{\circ}$ : "O ensino fundamental público terá como fonte adicional de financiamento a contribuição do salário-educação recolhida, na forma da lei, pelas empresas, que dela poderão deduzir a aplicação realizada no ensino fundamental de seus empregados e dependentes". Contudo, a emenda constitucional 14/96 altera esse dispositivo para a seguinte redação: "O ensino fundamental público terá como fonte adicional de financiamento a contribuição social do salário-educação, recolhida pelas empresas na forma da lei".

A proposta de conversão da Medida Provisória n. 399-E/06, que regulamenta a Emenda Constitucional n. 53/06 (FUNDEB), dispóe, em seu artigo 5, parágrafo $1^{\circ}$ : "É vedada a utilização dos recursos oriundos da arrecadação da contribuição social do salário-educação a que se refere o parágrafo $5^{\circ}$ do art. 212 da Constituição Federal na complementação da União aos Fundos". Trata-se, pois, de uma complementação para além da prevista no FUNDEB.

\section{IV}

As estatísticas da educação em geral e, especialmente, no ensino fundamental, apresentando resultados intoleráveis, o conhecimento de um processo histórico-educacional claramente seletivo e elitista e a política de descontinuidade administrativa nas políticas educacionais dos governos acenderam, entre acadêmicos e profissionais, a consciência da importância da educação. Esses fatores, ampliados em uma sociedade globalizada, em que a ciência se incorpora, de modo galopante, ao mundo macro ou micro da produção, tornaram inadiável a luta dos profissionais do ensino por melhores condiçôes de ensino/aprendizagem, incluídos aí seus salários. Daí a Constituiçăo da República de 1988 (CR/ 88) e a Lei de Diretrizes e Bases da Educação Nacional (LDBEN) conferirem tal relevância à educação que a eleva à categoria de princípio e de direito social (art. $6^{\circ} \mathrm{da} \mathrm{CR} / 88$ ), articulando-a com a proteção à cidadania e com a dignidade da pessoa humana (art. 205 e $3^{\circ}$ da CR/88).

Ora, esses princípios, confrontados com um retrato real alarmante, propiciaram à consciência coletiva que é irracional ficar nesse estado. A oportunidade para sair desse estado se deu em 1994, quando da Conferência 
Nacional de Educação, em que as temáticas-chave foram o Plano Decenal de Educação para Todos e a busca de um Acordo Nacional de Educação para Todos. Por um inédito consenso, emergiu do Acordo o Pacto pela Valorização do Magistério e Qualidade da Educação. Vários foram os compromissos assumidos seja por associaçóes e corporaçōes educacionais, seja por entidades governamentais de todos os entes federativos.

A tradução do Pacto de 1994, por meio do FUNDEF, representou a formalização de aspectos daquele pacto cujo estreitamento se deu não só pela menor disposição de diálogo, como também pelo não-cumprimento de pontos pactuados e pelo desembolso restrito de recursos claramente definidos na Lei n. 9.424/96, por parte da União. De todo modo, o FUNDEF representou um maior disciplinamento dos recursos vinculados e subvinculados; inclusive, para efeito de destinação do financiamento, criaram-se os Conselhos de Controle Social.

Duas iniciativas atuais de governo buscam recuperar aspectos do pacto de 1994, sem abandonar os pontos positivos advindos do FUNDEF.

O primeiro é o Fundo de Manutenção e Desenvolvimento da Educação Básica e de Valorização dos Profissionais da Educação (FUNDEB), por meio da Emenda Constitucional n. 53/2006. Ela preserva pontos positivos do FUNDEF, amplia sua abrangência para a educação básica em seus níveis e modalidades, dispõe prazo para fixar, em lei específica, piso salarial profissional nacional para os profissionais do magistério público, ${ }^{14}$ explicita em valores pecuniários a complementação da União, aperfeiçoa os Conselhos de Controle do Fundo, reitera a obrigação dos planos de carreira e remuneração, com capacitação profissional em que a formação continuada deve promover a qualidade do ensino.

O segundo é o Plano de Desenvolvimento da Educação (PDE), no qual o MEC assume um protagonismo compartilhado com os poderes públicos dos outros entes federativos. Nesse Plano, metas objetivas serão tomadas a partir de informaçōes e dados trazidos pelas avaliaçôes e indicadores feitos há 10 anos na educação básica. Essas metas, pactuadas por adesão com os entes federativos, terão o seu foco voltado para a aprendizagem e seus resultados com apoio na formação continuada. Resultados satisfatórios terão incentivos e resultados insatisfatórios terão o cuidado governamental para superação das deficiências.

Se tais medidas forem articuladas entre si, se a União mais uma vez não descumprir os termos desse novo pacto, se houver vontade de 
e recursos para efetivar tais propósitos e metas, é possível dizer que estamos vislumbrando uma saída racional para um direito proclamado como direito social.

\section{$\mathrm{V}$}

$\mathrm{O}$ que isso tudo significa em matéria de dever do Estado em suas políticas públicas para com a educação?

Em que pesem as alternativas já reiteradamente apontadas de aumento do porcentual do PIB para a educação, em que pesem as lacunas verificadas (que podem deixar de existir), o financiamento da educação escolar representa uma clara intervenção do poder público em uma área que se define como um direito da cidadania.

Essa intervenção, de caráter igualitário e universal, é, primeiramente, sobre o indivíduo, face ao ensino fundamental. Como ensino obrigatório, as pessoas na idade própria não têm escolha: ou vão para a escola ou vão para a escola. Bobbio (1987, p. 23) deixa claro essa dimensão impositiva da obrigatoriedade escolar:

Esta tentativa de escolher as reformas que são ao mesmo tempo liberadoras e igualitárias deriva da constatação de que há reformas liberadoras que não são igualitárias, como seria o caso de qualquer reforma de tipo neoliberal, que oferece ampla margem de manobra aos empresários para se desvencilharem dos vínculos que advêm da existência de sindicatos e comitês de empresa, ao mesmo tempo em que se destina a aumentar a distância entre ricos e pobres; por outro lado, existem reformas igualitárias que não são liberadoras, como toda a reforma que introduz uma obrigação escolar, forçando todas as crianças a ir a escola, colocando a todos, ricos e pobres, no mesmo plano, mas por meio de uma diminuição da liberdade.

Por sua vez, o Código Penal Brasileiro do Decreto-Lei n. 2.848, de 1940 , não deixa por menos. Os pais que não provêem a educação obrigatória incorrem em crime de abandono intelectual, de acordo com o artigo 246. E a legislação pertinente obriga as empresas a participarem da efetivação desse direito, cumprindo a função social da propriedade, conforme o artigo 170, III, e artigo 5, XXIII, da Constituição da República de $1988 .^{15}$

Por outro lado, o Estado continua tendo a competência privativa em relação ao caráter oficial dos certificados e diplomas da educação 
escolar $^{16}$ e daí advém o artigo 209 da mesma Constituição, pelo qual cabe ao Estado condicionar a autorização de funcionamento das escolas próprias da iniciativa privada à obediência às normas gerais da educação e submetê-las, tal como faz com as do sistema público, à avaliação de qualidade.

E, por ser direito público subjetivo, o poder público, face ao ensino obrigatório, não pode deixar de atender a todo o universo escolarizável. $O$ titular deste direito é qualquer pessoa, de qualquer idade, que não tenha tido acesso à escolaridade obrigatória na idade apropriada ou não. $O$ sujeito deste dever é o Estado. Assim, o direito público subjetivo explicita claramente a vinculação substantiva e jurídica entre seu titular e o sujeito do dever. Na prática, isso significa que qualquer criança ou adulto que não tenha entrado no ensino fundamental pode exigi-lo e o juiz deve deferir imediatamente, obrigando as autoridades constituídas a cumprilo: "O não cumprimento por parte das autoridades implica em responsabilidade da autoridade competente" (art. 208, \$2 ).

A mola insubstituível que põe em marcha este direito é (ou deve ser) a ação responsável do Estado e suas obrigaçôes. E como esse direito não poderia ser efetivado sem os recursos necessários, a originalidade do Brasil está em ter consignado, na Lei Maior, a fonte desses investimentos, conforme o artigo 212 .

Ora, esse conjunto de constrangimentos normativos tem um significado de Estado e, como decorrência, um sentido para as políticas públicas da educação. E esse significado está na presença de um ordenamento estatal, no qual já se deu a passagem do Estado liberal clássico para o Estado sócio-assistencial.

No primeiro, o Estado persegue a convivência entre indivíduos que buscam seus próprios fins individuais. Ele garante os interesses imersos no contrato, assegurando que esse tenha seu curso no campo próprio do privado. Nesse caso, se projeta a obediência às normas do direito privado e do direito penal como normas de conduta, ao mesmo tempo em que essa hegemonia tem como pressuposto ser a mais racional e benéfica à convivência social. Desse modo, o Estado mantém o interesse de cada um ao não interferir e ao não representar o interesse de nenhum dos contratantes.

No segundo, tem-se uma concepção oposta. Ao invés de ver a sociedade sob o modo contratual, cuja base é o indivíduo, tem-se como 
pilar ou a sociedade como um todo precedendo o indivíduo, ou a composição da sociedade em grupos sociais. Nesse caso, o interesse coletivo ou o bem comum expressam a melhor racionalidade como esforço conjugado de todos e comum a todos.

É da passagem do Estado liberal clássico para um Estado social, enfaticamente rejeitada por Hayek e seus discípulos, que se fez presente, no mundo capitalista, a coexistência das normas advindas do direito público com as do direito privado. É dela e das lutas que fizeram dela uma conquista que o Estado pôde interferir no sistema contratual de mercado e impor direitos sociais ao lado dos direitos civis e políticos, ou fazê-los tensionados por coexistirem entre si.

Essa tensão nasce tanto do fato da intervenção em si, quanto do fato de os direitos sociais, formalizados em lei, serem um investimento que possui um custo saído dos fundos públicos. Assim, se faz necessário apontar as fontes para o preenchimento desses fundos. Tais fontes, recolhidas ao Estado para serem revertidas à coletividade como um todo, sob a forma de serviços públicos, podem ser tanto impostos sobre contribuintes em suas mais diversas formas, quanto outras formas de tributação.

Nesse sentido, torna-se bastante improcedente acoimar o conjunto das políticas educacionais, no Brasil, como sendo caudatárias de um conservadorismo liberal. As reservas constitucionais do financiamento vinculado, a gratuidade no ensino oficial, o universalismo do direito ao ensino fundamental, seu caráter obrigatório para as pessoas de 6 a 14 anos e a competência privativa da certificação oficial para efeito de validade nacional não só contêm um horizonte equalizador, como também são amortecedores de políticas outras, tendentes a um conservadorismo social. O impacto de políticas liberalizantes em relação a direitos sociais torna-se diferenciado quando esses são protegidos por um ordenamento jurídico, cuja sustentação é a Constituição, que tem atrás de si uma longa história de pleitos, exigências e lutas.

São dimensões obrigatórias a serem respeitadas, sob pena de insegurança jurídica, mesmo que programas de governos possam querer quebrá-las ou atenuar seu âmbito de aplicabilidade.

Finalmente, a coexistência dessas dimensōes igualitárias com outras até mesmo opostas no âmbito do Estado indica a abertura deste a uma gama de novos interesses não redutíveis ao elitismo e seletividade estruturais do Estado liberal clássico. 
Estado e políticas de financiamento em educação

\section{Recebido em junho de 2007 e aprovado em julho de 2007.}

\section{Notas}

1. A descentralização do ensino primário se dá pelo Ato Adicional de 1834 (sobre o assunto, cf. Sucupira, in: Fávero, 1996). Essa descentralização se fez acompanhar do regime federativo quando da instauração da República.

2. Sobre a noção de sistemas no atual ordenamento jurídico, cf. Parecer CNE/CEB n. 30/00.

3. Aqui transparece o papel da Uniāo na complementação salarial negociada dos professores estaduais da zona rural, quando o estado-membro adere ao Convênio.

4. A primeira intervenção direta e financiada pela União no ensino primário se dá mediante decretos federais em escolas do Sul do país, em que havia forte presença de população imigrada. Cf. Decretos n. 13.175/1918; $13.390 / 1919$ e 13.460/1919.

5. Sobre a educação no período, cf. Rocha (in: Fávero, 1996) e Cury (1988).

6. Aqui comparece a exigência da instalação de um fundo, ou melhor, de fundos estaduais junto com um fundo federal. Como se sabe, no setor público, um fundo é constituído de recursos monetários destinados ao desenvolvimento de uma área específica.

7. Sobre a obrigatoriedade, cf. Horta (1998).

8. Sobre essa Constituição, cf. Cury (1988).

9. Refiro-me à Constituição de 1967.

10. Pode-se estar sob uma ditadura sem necessariamente servir a ela (cf. Horta, 1994; Schwartzman, 1984; Nunes, in: Bomeny, 2001).

11. Para uma biografia desse ilustre baiano chamado Mario Augusto Teixeira de Freitas (1890-1956), cf. Fávero e Medeiros (1999, p. 393-401).

12. Sobre essa Conferência, cf. Horta (in: Gomes, 2000, p. 143-172).

13. Para uma biografia de Anísio Teixeira, cf. Nunes (in: Fávero \& Britto, 1999) e Cury (2000).

14. O projeto de Lei, regulamentando o artigo 214 da Constituição da República, está no Congresso Nacional.

15. A função social da propriedade já comparece na Constituição de 1934, no artigo 113, inciso 17, e na Constituição de 1967, artigo 157, III.

16. Essa competência só foi desfeita, ainda assim de modo não absoluto, na chamada Reforma Rivadávia, entre 1911-1915. Sobre esse assunto, cf. Marques Jr. (1967).

\section{Referências bibliográficas}

\section{AZEVEDO, F. et al. A reconstrução educacional no Brasil: ao povo e ao governo; manifesto dos Pioneiros da Educação Nova. São Paulo: Nacional, 1932.}


BOBBIO, N. Reformismo, socialismo e igualdade. Novos Estudos CEBRAP, São Paulo, n. 19, dez. 1987.

BOMENY, H. (Org.). Constelação Capanema: intelectuais e políticas. Rio de Janeiro: FGV; Bragança Paulista: EDUsf, 2001.

CHIZZOTTI, A. A Constituinte de 1823 e a educação. In: FÁvero, O. (Org.). A educação nas constituintes brasileiras 1823-1988. Campinas: Autores Associados, 1996.

CURY, C.R.J. Ideologia e educação brasileira: católicos e liberais. 4. ed. São Paulo: Cortez, 1988.

CURY, C.R.J. et al. Medo à liberdade e compromisso democrático: LDB e Plano Nacional de Educação. São Paulo: Pioneira, 1997.

CURY, C.R.J. A Constituição de Weimar: um capítulo para a educação. Educação \& Sociedade, Campinas, v. 19, n. 63, p. 83-104, ago. 1998.

CURY, C.R.J. Anísio Teixeira. Prospects, Genebra, v. 30, n. 4, p. 509520, dec. 2000.

CURY, C.R.J. Cidadania republicana e educação: governo provisório do mal. Deodoro e Congresso Constituinte de 1890-1891. Rio de Janeiro: DP\&A, 2001.

CURY, C.R.J. A educação na Revisão Constitucional de 1925-1926. Bragança Paulista: EDUSF, 2003.

FÁVERO, M.L.A.; BRITTO, J.M. (Org.). Dicionário de educadores no Brasil. Rio de Janeiro; UfRJ; Brasília, DF: INEP, 1999.

FÁVERO, O. (Org.). A educação nas constituintes brasileiras: 18231988. Campinas: Autores Associados, 1996.

GOMES, A.M.C. (Org.). Capanema: o ministro e seu ministério. Rio de Janeiro: FGV; Bragança Paulista: EDUSF, 2000.

GOMES, A.M.C. Propaganda política, construção do tempo e do mito Vargas: o calendário de 1940. In: BAstos, E. et al. (Org.). Intelectuais sociedade e política: Brasil-França. São Paulo: Cortez, 2003.

HORTA, J.S.B. O hino, o sermão e a ordem do dia: a educação no Brasil (1930-1945). Rio de Janeiro: UFRJ, 1994. 
HORTA, J.S.B. Plano Nacional de Educação: da tecnocracia à participação democrática. In: CuRY, C.R.J. Medo à liberdade e compromisso democrático: LDB e Plano Nacional de Educação. São Paulo: Pioneira, 1997. p. 137-206.

HORTA, J.S.B. Direito à educação e obrigatoriedade escolar. Cadernos de Pesquisa, São Paulo, n. 104, p. 5-34, jul. 1998.

HORTA, J.S.B. A I Conferência Nacional de Educação ou de como monologar sobre a educação na presença de educadores. In: GOMES, A.M.C. (Org.). Capanema: o ministro e seu ministério. Rio de Janeiro: FGV; Bragança Paulista: EDUSF, 2000.

KELLY, C. Notícia histórica. In: PLANO Nacional de Educação. Rio de Janeiro: MEC, 1963.

MARQUES JUNIOR, R. Política educacional republicana: o ciclo de desoficialização do ensino. 1967. Tese (Doutorado) - Faculdade de Filosofia, Ciências e Letras, Universidade Estadual Paulista, Araraquara.

MARSHALL, T.H. Cidadania, classe social e status. Rio de Janeiro: Zahar, 1967.

NAGLE, J. Educação e sociedade na Primeira República. São Paulo: EDUSP, 1974.

NUNES, C. Anísio Spinola Teixeira. In: FÁvero, M.L.A.; Britto, J.M. (Org.). Dicionário de educadores no Brasil. Rio de Janeiro: UfRJ; Brasília, DF: INEP, 1999.

NUNES, C. As políticas de educação de Gustavo Capanema no Governo Vargas. In: Bomeny, H. (Org.). Constelação Capanema: intelectuais e políticas. Rio de Janeiro: FGV; Bragança Paulista: EDUSF, 2001.

PASQUALE, C. Que é salário-educação?: como funciona o sistema. Revista Brasileira de Estudos Pedagógicos, Rio de Janeiro, v. 7, n. 29, p. 5-24, jan./fev. 1965.

PRZEWORSKI, A. Capitalismo e social-democracia. São Paulo: Cia. das Letras, 1989.

ROCHA, M.B.M. Tradição e modernidade na educação: o processo constituinte de 1933-34. In: FÁvero, O. (Org.). A educação nas constituintes brasileiras: 1823-1988. Campinas: Autores Associados, 1996. 
SAVIANI, D. Educação brasileira: estrutura e sistema. Campinas: Autores Associados, 2004.

SCHWARTZMAN, S. et al. Tempos de Capanema. Rio de Janeiro: Paz \& Terra; São Paulo: Edusp, 1984.

SUCUPIRA, N. O Ato Adicional e a descentralização. In: FÁvero, O. (Org.). A educação nas constituintes brasileiras: 1823-1988. Campinas: Autores Associados, 1996.

TEIXEIRA, A. Educação é direito. Rio de Janeiro: Nacional, 1968. 